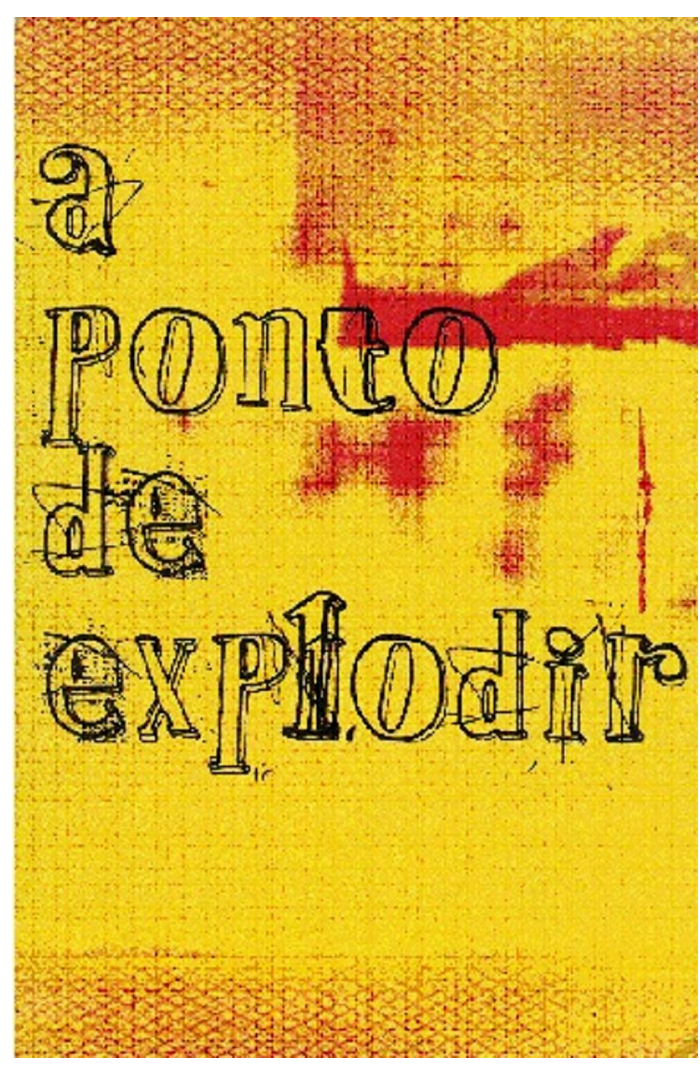

Capa do livro

\title{
A explosão da literatura de Sérgio Fantini
}

\section{Maria José de Castro Alves}

Licenciada em Letras (Língua Portuguesa e Literatura) pela Newton Paiva. Especializanda em Língua Portuguesa: Ensino de Leitura e Produção de Textos pela FALE/UFMG. Coordenadora do Setor Linha Editorial Tela e Texto do Programa de Ensino, Pesquisa e Extensão A tela e o texto.

FANTINI, Sérgio. A ponto de explodir. Belo Horizonte, Segrac Editora e Gráfica Ltda., 2008.

Para o leitor que não conhece o estilo de Sérgio Fantini, a leitura inicial dessa obra causa choque e estranheza. Mas, aos poucos, ele será seduzido pela capacidade do texto de sugá-lo para o reino das palavras. E passará, de espectador, a sujeito participativo frente às histórias narradas. 
O estilo intimista da obra descreve o micro-universo que permeia os pensamentos dos personagens em seu cotidiano - as coisas do dia-a-dia, da rua, do bairro, do casamento, da vida em família e da solidão. Quando dá conta de si, o leitor já embarcou na viagem. Tanto os sonhos de moleques e a inconseqüência da adolescência quanto a violência e a irresponsabilidade de um jovem em conflito são partes da crueldade de uma realidade dura. Além disso, a forma de o livro narrar a solidão e a alienação quebra certos padrões estabelecidos pela sociedade.

Essa narrativa também apresenta aspectos memorialísticos. Em "Pegador", o conto narrado deixa em aberto para o leitor utilizar a imaginação e completar com a verdade possível de ações que sugerem realidade e ficção. Saber se os fatos aconteceram ou não ficará a cargo do leitor, não mais do narrador. Tem-se que ler para se envolver e completar a história. Uma coisa é certa - passa a haver uma identificação entre o leitor e o autor porque o texto trata de temas caros a todos nós, como a infância:

\begin{abstract}
$\mathrm{Na}$ rua em que cresci havia muitas crianças. Havia também os vendedores de quebra-queixo, de biju, de pirulito de café, de pipoca, de enciclopédia e de dobradinha, além do amolador de facas... Claro que minha infância não foi só uma bala delícia derretida no céu da boca, mas trago tantas lembranças agradáveis... um beijo de meu pai quando tive febre alta, a primeira vez que fui sozinho à padaria...
\end{abstract}

Nas entrelinhas da obra, encontramos uma espécie de saudosismo, uma certa melancolia. Também presenciamos um grito de fúria, de revolta contra a destruição da natureza e contra a violência urbana. Há uma premente necessidade de adaptação aos novos tempos, à modernidade, além de impotência e pequenez diante da falta de controle sobre o rumo que as coisas vão tomando. Sérgio Fantini mostra, em "Seu deus não é o meu", a necessidade de se atentar para o que não está escrito:

Vivo num tempo estranho. As coisas não são como são. Muito menos são como eles nos contam. É preciso atentar para as entrelinhas. Mas também não estou preocupado com As Grandes Verdades ou o Destino da Humanidade. Minha atenção está nos vizinhos, no meu bairro. Sou um deles, parte deste mundinho. Pode ser pequeno, mas é o único que tenho. Ele precisa de mim para existir e eu preciso dele para ser o que sou.

- recurso da frase inacabada é muito interessante em "Diário do inclame", pois o leitor completa o texto a seu bel prazer, e é um prazer enorme entrar nessa brincadeira. 


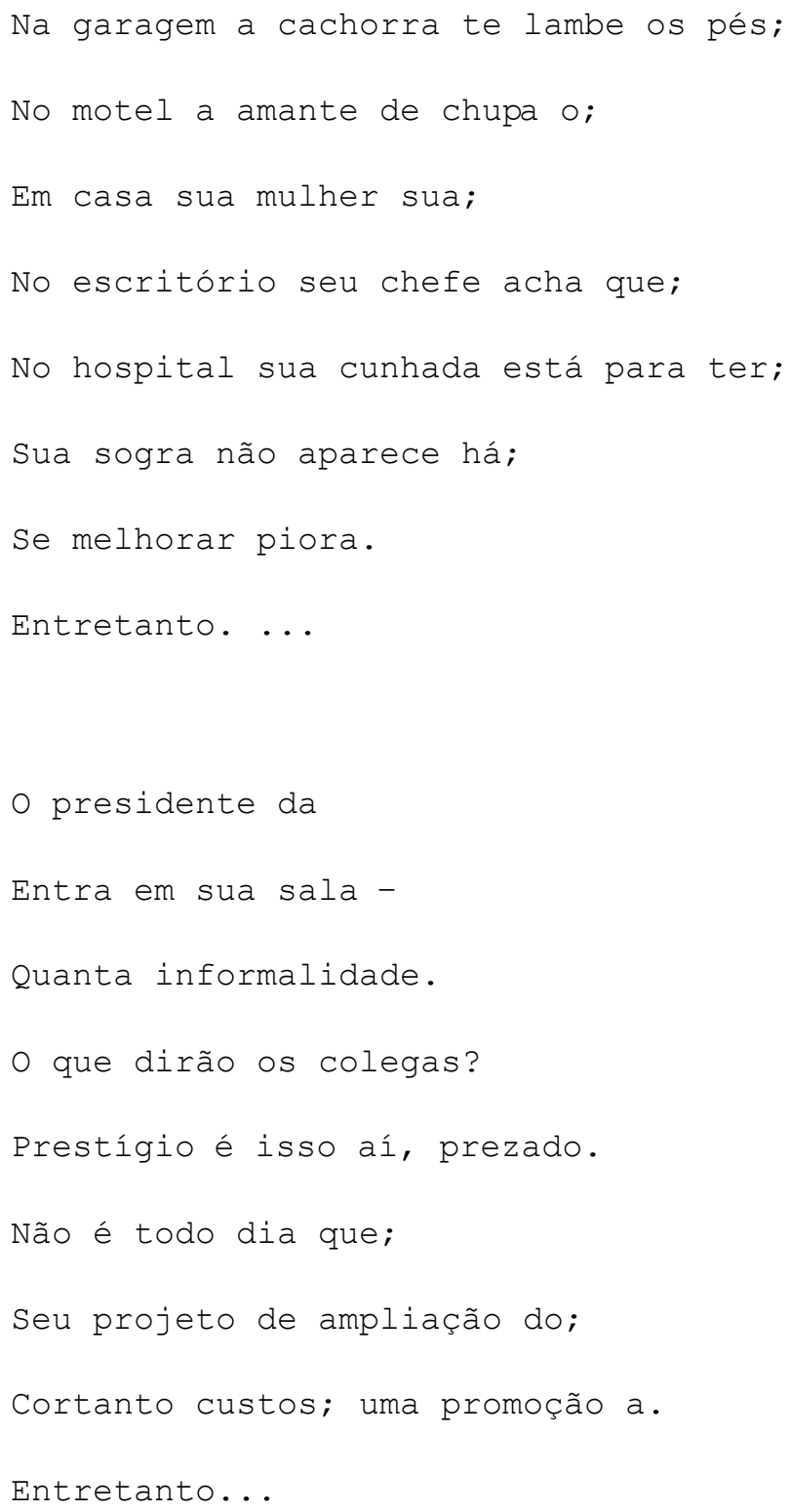

A falta de pontuação sugere a falta de pausa que há nos dias de hoje, na vida moderna, na correria do dia-a-dia. A irreverência presente no não uso de maiúsculas pode determinar a tentativa de promover, pela igualdade textual, a crítica à desigualdade humana, como podemor ver em "John goes, bells":

quando john lennon morreu, eu ainda não sabia disso: estava zanzando pelo centro da cidade com um copo de vinho na mão e...

[...] mas aquela foi uma noite ruim de um dia duro: acabei 


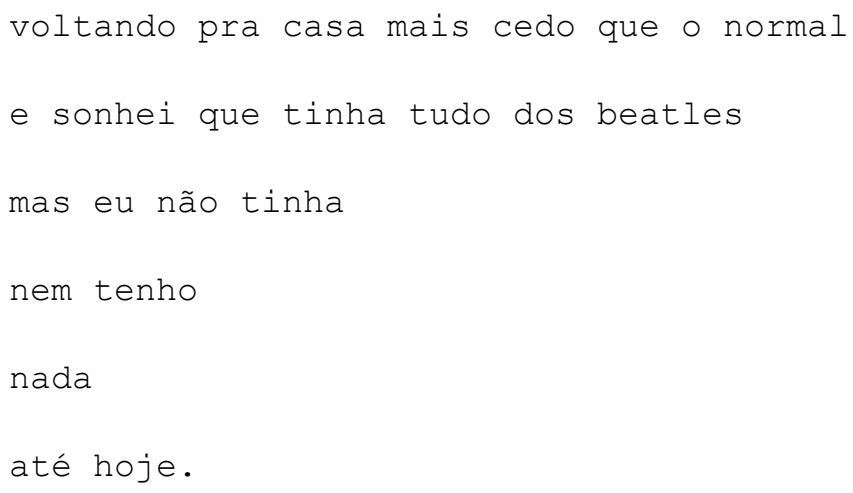

A respeito dessa obra, Ernani Ssó afirma, de modo taxativo, na quarta capa do livro: "Acho que foi Henry Miller que disse que um escritor deve viver como um cordeiro e escrever como um tigre. É mais ou menos o que Sérgio Fantini faz: pessoalmente, é a simpatia. Escrevendo? Um perigo."

A ponto de explodir já explodiu. É uma explosão de emoções e experiências não apenas de um indivíduo chamado sérgio, mas do escritor Fantini que, cordeiro-e-tigre, registra histórias de muitas vidas - das suas e das nossas. Por isso, é um livro que vai provocando, no leitor, pequenas explosões de lembranças e, nesse micro movimento estético, associa indelevelmente ficção e vida. 